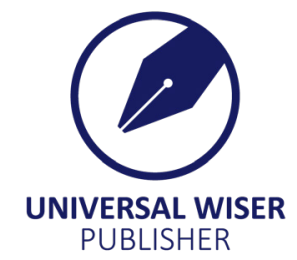

\title{
Benefits of School-Based Assessment in the Learning of Social Studies
}

\author{
Jacob Issaka $^{1^{*}}$, Daniel Kwesi Hammond ${ }^{1}$, Patrick Yeyie $^{2}$, Prosper Kofi Agroh ${ }^{1}$ \\ ${ }^{1}$ Jasikan College of Education, Jasikan, Ghana \\ ${ }^{2}$ Kibi Presbyterian College of education, Kibi, Ghana \\ E-mail: jacsak73@yahoo.com
}

\begin{abstract}
The Ghana government proposed to implement school-based assessment (SBA) in all pre-tertiary education institutions to replace the continuous assessment in 2007. However, any research is yet to be conducted in Biakoye District to find out the benefits of school-based assessment in the teaching and learning of Social Studies. This study examined the benefits of school-Based Assessment as an innovation in Ghanaian educational system in the learning of Social Studies. The descriptive survey was adopted by the study. A total of 40 Social Studies teachers from Biakoye District were purposively selected for the study. It was found that even though the majority of the Social Studies teachers have never attended workshop on the use of SBA, they implemented it in assessing students. The Social Studies teachers used for the study also indicated that the SBA has a lot of benefits in the teaching and learning of Social Studies. The study recommends that workshops should be organized for teachers on SBA so that they could use it effectively.
\end{abstract}

Keywords: formative assessment, school-based assessment, social studies teachers, summative assessment, teaching and learning

\section{Introduction}

Assessment is a very powerful tool to ensure quality education. It is a process for obtaining information that is used to make decision about students, curricula and educational programme ${ }^{[1]}$. Assessment in education is the process of gathering, interpreting, recording, and using information about pupils' responses to an educational task ${ }^{[2]}$. Assessment is a powerful and strong tool that can enhance learning, depending on how it is implemented. It is used to monitor the quality of the educational system, evaluate educational policies and programmes, certify students' learning achievement and review the educational system ${ }^{[3]}$. Assessment provides relevant feedback on students' learning outcomes and influences the improvement of the learning ${ }^{[4]}$. Assessment helps students to be involved in their own progress, enables them to monitor their performance and provides feedback to their parents ${ }^{[5]}$. Teaching, learning and assessment are inextricably linked and therefore inseparable.

There are various ways of collecting information for the purpose of assessment. Some of these include tests / quizzes, class exercises, homework, project and laboratory work ${ }^{[1]}$. In order to ensure the effectiveness of assessment, teachers are encouraged to use varied modes of assessment while focusing on the rationale of the assessment ${ }^{[4]}$.

The use of assessment to promote quality education cannot be overemphasized. Therefore, assessment is one of the key quality indicators in education. It is a major sub-division of professional practice domain under the national teachers' standards for Ghana. Teachers are required to possess certain competences in assessing students ${ }^{[6]}$.

In Ghana, to make assessment more efficient and effective in order to accomplish quality education at the pre-tertiary level, the Ministry of Education introduced the School-Based Assessment (SBA) in 2007 into the curriculum to replace the continuous assessment (CA) system. School based assessment according to Onuka and Oludipe ${ }^{[7]}$ is an assessment practice that broadens and expands the forms, mode, means and scope of assessment in school in order to facilitate and enhance learning by providing immediate feedback ${ }^{[8]}$.

Under the SBA system, teachers are given greater responsibility to design quality assessments that align with the learning outcomes as they are the most suitable people to assess their students and they have a better understanding of the context of the subject matter ${ }^{[5]}$. This does not only provide teachers the opportunities to continuously monitor their students learning outcomes but also enables them to give constructive feedback to improve students' learning abilities ${ }^{[9]}$. Based on the assessment outcomes, teachers can make vital decision whether to continue with a new topic or send the

Copyright (C2020 Jacob Issaka, et al.

DOI: https://doi.org/10.37256/ser.122020458

This is an open-access article distributed under a CC BY license

(Creative Commons Attribution 4.0 International License)

https://creativecommons.org/licenses/by/4.0/ 
more academically challenged students to remedial class. Indirectly, teachers have to develop series of effective assessment strategies to enhance the learning for students with different abilities ${ }^{[10]}$. But this way, students are able to progress according to their ability; good students progressing faster and weaker students are given more time in order to fulfill the learning expectations.

The SBA system is designed to provide schools with an internal assessment system that will help schools to standardize the practice of internal school-based assessment in all schools in the county and reduce assessment tasks for each of the school subjects. It is also meant to provide teachers with guidelines for constructing assessment items and guidance in marking and grading of test items and other assessment tasks. In addition, it introduces a system of moderation that will ensure accuracy and reliability of teachers' marks ${ }^{[11]}$. It also provides teachers with guidance on how to conduct remedial instruction on difficult areas of the syllabus to improve pupils' performance ${ }^{[12]}$.

Apart from the SBA, teachers are expected to use class exercises and home work as processes for continually evaluating pupils' class performance, and as a means for encouraging improvements in learning outcomes.

\section{Statement of problem}

Assessment is the heartbeat of education and cannot be separated from teaching and learning. This is why assessment and learning are inseparable as each informs the other. Assessment determines the success or failure of a student in formal education system. In other words, assessment determines the learning outcomes of a student and his or her progression on the educational ladder and to some extent job placement. Therefore, the role assessment plays in the students' life cannot be underestimated.

There are two major forms of assessment namely formative (SBA) and summative assessment ${ }^{[1,2]}$. The SBA is carried by teachers in the various schools using guidelines provided in the syllabus. Basic school Social Studies teachers and their students therefore need to understand the nature of SBA and the role it plays in improving teaching and learning and how it consequently optimizes academic performance ${ }^{[13]}$. Effective use of SBA helps to meet diverse learning needs of students ${ }^{[14]}$.

However, the use of SBA in the teaching and learning has been misunderstood both in theory and in practice by many teachers across countries ${ }^{[15]}$. The basic school Social Studies teachers in Biakoye District are not exception from the above issue. Thus, the inability of Social Studies teachers in the district to adopt the SBA system effectively could affect the realization of training responsible citizens who are well-informed, concerned, reflective and participatory citizens which is the main goal of Social Studies ${ }^{[16,17]}$.

The basic school Social Studies teachers in the Biakoye district seem not to have adequate understanding of SBA system and how it can be used to attain the desired goals of learning the subject. This situation stems from the fact that SBA was introduced without adequate training given to the teachers ${ }^{[12,18]}$.

According to Yidana and Boadu ${ }^{[19]}$ Social Studies is about problem solving and that it's teaching and assessment should be based on the problem-solving approach. He suggests that Social Studies teachers should endeavour to engage their students in inquiries into problems affecting the survival of the society ${ }^{[17,20]}$.

The Junior High School Social Studies syllabus developed by National Council for Curriculum and Assessment ${ }^{\text {[20] }}$ states that assessment should be comprehensive. This means that the assessment must satisfy profile dimensions ${ }^{[2]}$. Profile dimensions describe the underlying behaviours for teaching, learning and assessment. In Social Studies, the profile dimensions for teaching, learning and assessment at the basic education level are Knowledge and Understanding (25\%), Use of Knowledge (25\%) and Attitudes and Values (50\%).

Each of the dimensions has been given a percentage weight that should be considered in teaching, learning and assessment. The weights of the dimensions show the relative emphasis that the Social Studies teacher should give in the teaching, learning and assessment processes in the subject. Combining the dimensions in the teaching, learning and assessment ensures that Social Studies is taught and studied not only at the cognitive level, but also leads to the acquisition of positive attitudes and values on the part of pupils ${ }^{[11]}$.

In social studies, more weight is on the development of attitudes and values and this could only be achieved through the effective use of the guidelines spelt out in the SBA. It is through this, that the goal of Social Studies in producing concerned, committed and participatory citizens could be achieved ${ }^{[17]}$. This could only be realised when Social Studies teachers effectively use SBA approach, where learners are offered the opportunity to investigate or explore around problems by engaging in appropriate activities that eventually help them discover solutions to problems by themselves. Project activities under the SBA are effective learning strategies because they do not only develop critical thinkers but help in the acquisition of positive attitudes and values that are required in solving real-world problems ${ }^{[21]}$.

The assessment in Social Studies is mostly centred on the cognitive domain neglecting the affective domain ${ }^{[2]}$. 
The question still remains that how do Social Studies teachers in the Biakoye District effectively use the SBA and how this impacts on students' learning outcome. The study therefore, examined the use of SBA system and its benefits on pedagogical development and students' learning outcomes.

\section{Models of school-based assessment}

Bell and Cowie ${ }^{[22]}$ propose two models of SBA. They are planned assessment and interactive assessment. In the process of planned assessment, the teachers plan to use various assessment strategies to gather information about students' learning outcomes. In this case, there is assessment plan that the teachers follow ${ }^{[23]}$. Interactive school-based assessment on the other hand occurs during student-teacher interactions. Unlike planned school-based assessment with pre-determined assessment activities, interactive assessment arises out of a learning activity. This research sees this model as relevant because the school-based assessment system in Ghana is based on both planned and interactive assessments. In the SBA, teachers design assessment plan that they follow. However, in some cases some assessment tasks are carried out though they are not in the assessment plan.

In addition, Harlen ${ }^{[19]}$ formative cyclical assessment model was also adapted. The model is in a cycle form with the student at the centre of teaching, learning and assessment process. The first thing in this model is that the teacher needs to set objectives that will be assessed by ensuring that the student is at the centre of the assessment process. Thereafter, evidence needs to be collected from students and interpreted to make value judgment. This will help the teacher to decide the next appropriate activities. The SBA system is in line with this model and this makes it relevant for the study.

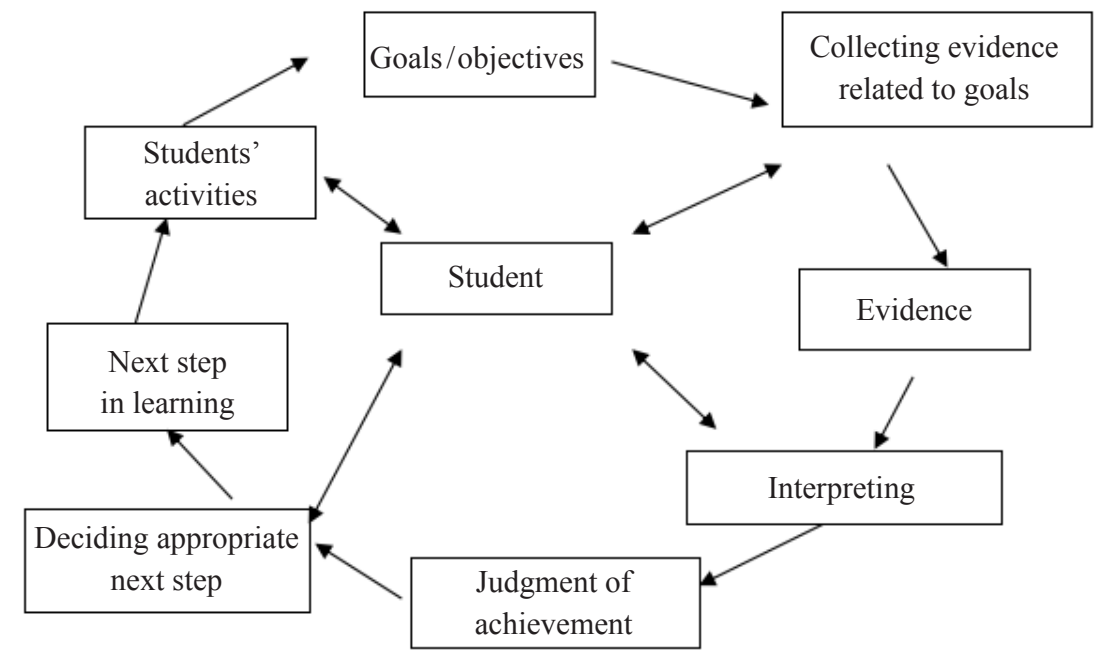

Figure 1. Adapted Harlen ${ }^{[24]}$, formative assessment cycle

\section{School-based assessment in Ghana}

Assessment in education refers to a process of obtaining information that is used for making decisions about students, curricula, programmes and educational programmes and policies. According to them the information could be gathered through observation, test, homework, project and laboratory work. Awoniyi and Fletcher ${ }^{[25]}$ opine that assessment is a process of gathering evidence of what a student can do in order to provide feedback for improvement. On their part Boadu and Asare-Danso ${ }^{[2]}$ see assessment as an attempt to measure some particular ability, knowledge, skill or attitude that the learner may or may not possess. According to Boadu and Asare-Danso ${ }^{[2]}$, assessment could take the form of test, home / assignment, projects and observation.

\section{Nature of school-based assessment}

The Junior High School Social Studies syllabus of the Ministry of Education, Science and Sports ${ }^{[26]}$ (2007), states that the SBA system consists of 12 assessments a year instead of the 33 assessments in the previous continuous assessment system. This means a reduction by $64 \%$ of the work load compared to the previous continuous assessment system.

The 12 assessments are labelled as Task 1, Task 2, Task 3 up to Task 12. Task 1-4 are supposed to be administered in Term 1; Tasks 5-8 in Term 2, and Tasks 9-12 in Term 3. Task 1 will be administered as an individual test at the end of 
the first month of the term. The equivalent of Task 1 will be Task 5 and Task 9 to be administered in Term 2 and Term 3 respectively. Task 2 (also Task 6 and Task 10 for Term 2 and Term 3 respectively) will be administered as a group work and will consist of two or three instructional objectives that the teacher considers difficult to teach and learn. The selected objectives could also be those objectives considered very important and which therefore need pupils to put in more practice. Task 2 will be administered at the end of the second month in the term. Task 3 (and also Task 8 and Task 11 for Term 2 and Term 3 respectively) will also be administered as individual test under the supervision of the class teacher at the end of the $11^{\text {th }}$ or $12^{\text {th }}$ week of the term. Task 4 (and also Task 8 and Task 12) will be a project to be undertaken throughout the term and submitted at the end of the term. Schools will be supplied with 9 project topics divided into three topics for each term. A pupil is expected to select one project topic for each term. Projects for the second term will be undertaken by teams of pupils as group projects. Projects are intended to encourage pupils to apply knowledge and skills acquired in the term to write an analytic or investigative paper to solve a problem or produce a product ${ }^{[11]}$.

Assessment should be viewed as a tool to improve the effectiveness of teaching and learning process ${ }^{[27]}$. The purpose of assessment is to find out if the objectives set for the lesson have been achieved ${ }^{[28]}$. According to Asemanyi and WatsonNortey ${ }^{[14]}$, assessment should not only be used to determine what students have learnt but also guide them to improve on their learning. It should serve as a mean to attain educational goals.

SBA is an ideal assessment system that relieves students' pressure while at the same time allowing teacher initiative in assessing their students. SBA ensures that teachers are fully involved in the assessment processes of their students. To promote the benefits of the assessment, teachers are expected to be involved in four phases of the assessment process: (a) planning, (b) gathering evidence, (c) interpreting evidence, and (d) using the results for decision making ${ }^{[24]}$. SBA ensures that teachers verify learners' performance and use feedback to improve learning outcomes ${ }^{[29]}$.

The SBA system is designed to standardize assessment practices, reduce assessment tasks, provide teachers with assessment guidelines, provide guidance in marking and grading of assessment tasks and to introduce a system of moderation that will ensure accuracy and reliability of teachers' marks ${ }^{[11]}$.

The benefits for using SBA include providing stable and continuous pressure-free assessment, reducing the reliance on standardized examination, improving test item reliability, reflecting students' ability, fostering teaching, enforcing independent learning, facilitating learning autonomy and empowering teachers in the evaluation process ${ }^{[5]}$.

Another important benefit of SBA is that students themselves are evaluated based on activities carried out in the school and not on nationwide information assumption on what ought to have been learnt. Students are not compared to students in other schools when school-based assessment is used. School-based assessment can be made to include only what has been accomplished by the students and the outcome reflects what the students have actually learned, instead of what they were supposed to learn ${ }^{[14]}$.

Yong and Lim ${ }^{[27]}$ point to the fact that SBA brings about improvements in the teaching and learning processes. They indicate that SBA provides useful feedback on the teaching and learning processes and enables teachers to be more involved in the assessment process. Assessment greatly influences teaching and learning, and narrowing assessment means narrowing teaching and learning. Thus, integrating varied assessment modes into daily practice is useful in assessing the performance of students as well as the teaching and learning process ${ }^{[28]}$.

Assessment should serve as a means to attain educational goals. SBA has the characteristics that fulfill the above requirement. And it is the ideal assessment system to relieve students' pressure while at the same time allowing teacher initiative in assessing their students.

\section{Objectives of the study}

The objectives of the study are:

1. To assess the extent to which Social Studies teachers in Biakoye District follow the SBA guidelines.

2. To identify the benefits of using SBA in teaching and learning of Social Studies.

3. To suggest ways to improve the use of SBA in the teaching and learning of Social Studies.

\section{Methods}

The descriptive survey design was adopted by the study because according to Whyte ${ }^{[19]}$ descriptive survey is suitable for collecting data for qualitative research. According to Dada et al. ${ }^{[30]}$ descriptive survey involves the collection of data from a defined population to describe the present condition of the population using variables under the survey. The descriptive survey design was the ideal design for this research because it helped the researchers draw meaningful 
conclusions from the study ${ }^{[31]}$.

The target population for the study encompassed forty-two (42) Junior High schools (JHS) Social Studies teachers from public schools in Biakoye district. The teachers from the district were conveniently selected for the study on the grounds of proximity and familiarity. Schools in the district are partner schools of Jasikan college of Education where the researchers regularly visit to monitor the activities of their mentees on teaching practicum.

All the forty two (42) JHS Social Studies teachers from the public schools in the Biakoye District were selected for the study. Purposive sampling as a non-probability sampling technique was used to select the respondents. This is where respondents are selected because of their convenient accessibility and proximity to the researcher ${ }^{[6]}$. Also, many researchers prefer to use purposive sampling procedure because it is fast, inexpensive, easy and the subjects are readily available ${ }^{[2]}$. Since the research problem was on Social Studies, only Social Studies teachers were selected since they are familiar with the way they assess students in the subject.

The questionnaire and interview were the main data collection instruments which were used. Gray ${ }^{[32]}$, states that a questionnaire is a written list of questions, the answers to which are recorded by respondents. In questionnaire, respondents read the questions, interpret what is expected and then write down the answers.

Some advantages in using questionnaire include low cost, inflow of data and convenience ${ }^{[2]}$. Multi-method questions of close-ended and open-ended types were used. In order to design a valid questionnaire, a researcher must consider in detail the information he or she is seeking to draw out of the data, in conjunction with the research questions. The questionnaire was put into 6 sections as follows: Personal data, training on assessment, assessment procedures, forms of assessment, benefits of SBA and recommendations. The researchers distributed the questionnaires personally to the teachers in the various schools. They waited and collected the completed questionnaires in order to ensure high return rate.

Ten (10) of the Social Studies teachers selected were interviewed. Interviews produce detailed information that gives a deeper understanding of the phenomenon ${ }^{[33]}$.

\section{Validity of the instruments}

The instruments were given to experts in the field of educational measurement and evaluation and Social Studies to examine in order to establish both face and content validity. The instruments were re-designed based on the comments from the experts.

\section{Presentation and discussion of results}

The descriptive statistical analysis was employed by the study. The questionnaires were first edited to identify and eliminate errors made by the respondents. Out of the 42 questionnaires distributed, 40 were successfully completed. These completed questionnaires were used for the analysis. The analysis was based on the research objectives.

\section{Extent to which Social Studies teachers follow the SBA guidelines}

The current assessment practice in basic schools in Ghana is the SBA. One of the objectives of the research was to find out how effectively the social studies teachers in Biakoye district use the SBA system. The researchers wanted to know the extent to which Social Studies teachers follow the SBA guidelines in the syllabus. The interview results show that the teachers sometimes followed the SBA guidelines spelt out in the syllabus. However, in some cases they did not follow the SBA guidelines as a result of certain activities.

We sometimes follow what is stated in the syllabus especially for the quizzes and projects. But you know sometimes, you are not able to follow because of certain activities. You know what is stated in the syllabus is a suggestion... yes you are not a slave to the syllabus. We adjust sometimes because of our peculiar situation. For instance, the syllabus may say conduct a quiz during the fourth week of the term but sometimes it could happen... and the quiz cannot be conducted. As for me, I give my students a lot of assignments. The work is very tedious but you know the pay is small. We are doing our best (Field interview, participant \#1).

Yes I follow the guidelines spelt out in the Social Studies syllabus. There is time for the assignments, quizzes and projects and I follow that. My Headmaster is very strict on assessment. He has been checking that. But sometimes some cocurriculum activities prevent us from doing this as planned. One thing you have to know is that our children are lazy. They don't like learning. Always play. You give them assignment and sometimes they will not do it and now you are not allowed to cane them, yes that is the cause of the indiscipline (Field interview, participant \#8).

Yes I tried my best to follow the guidelines but it is not easy. You cannot strictly follow what is stated in the syllabus 
but we follow it sometimes. In this community, the children are not serious with their education. Sometimes one month after re-opening of school, some of the children have not reported, How will you conduct a quiz for them (Field interview, participant \#10).

The teachers were asked whether they have had any training in the use of the SBA system and the response from 33 of them representing $83 \%$ was in the negative. This might affect their understanding on how to use the SBA effectively. The responses of the teachers on the conduct of SBA are displayed in Table 1.

Table 1. Conduct of SBA by Social Studies teachers in Biakoye District

\begin{tabular}{|c|c|c|c|c|c|c|c|c|c|c|}
\hline \multirow[b]{2}{*}{ Item } & \multicolumn{2}{|c|}{1} & \multicolumn{2}{|c|}{2} & \multicolumn{2}{|c|}{3} & \multicolumn{2}{|c|}{4} & \multicolumn{2}{|c|}{5} \\
\hline & $\mathrm{F}$ & $\%$ & $\mathrm{~F}$ & $\%$ & $\mathrm{~F}$ & $\%$ & $\mathrm{~F}$ & $\%$ & $\mathrm{~F}$ & $\%$ \\
\hline I have assessment plan & & & 29 & 72.5 & & & 11 & 27.5 & & \\
\hline I discuss my assessment plan with my students & & & 34 & 85 & & & 6 & 15 & & \\
\hline I follow my assessment plan & & & 32 & 80 & & & 6 & 15 & 2 & 5 \\
\hline My assessment satisfies the weighing of profile dimensions & & & & & & & 25 & 62.5 & 15 & 37.5 \\
\hline I link assessment practices to instructional goals & & & & & & & & & 40 & 100 \\
\hline I strictly follow the SBA guidelines spelt out in the syllabus & & & 15 & 37.5 & & & 25 & 62.5 & & \\
\hline I adopt different assessment tasks & & & 7 & 17.5 & & & 28 & 70 & 5 & 12.5 \\
\hline I provide feedback to students after assessing. & & & 7 & 17.5 & & & 24 & 60 & 9 & 22.5 \\
\hline I use evidence gathered to determine the next instructional method & & & & & & & 5 & 12.5 & 35 & 87.5 \\
\hline
\end{tabular}

1. Strongly disagree, 2. Disagree, 3. Uncertain, 4. Agree, 5. Strongly agree

It could be seen from Table 1 that all the teachers strongly agreed that they link assessment practices to instructional goals while 87.5 also strongly agreed that they use evidence gathered from SBA to determine the next instructional method. In addition, Table 1 shows that majority of them agreed that they follow the SBA guidelines spelt out in the syllabus, adopt different assessment strategies ${ }^{[9]}$, provide feedback to students after assessing and their assessments satisfy the weighing of profile dimensions. Awoniyi and Fletcher ${ }^{[5]}$ opine that assessment involves gathering evidence of what a student can do in order to provide feedback for improvement and adopt effective strategies. Table 1 however shows that 29 of the respondents $(72.5 \%)$ indicated that they do not have assessment plan while majority of them $(85 \%)$ also disagreed that they discussed the assessment plan with their students. This might affect the effectiveness of the assessment. Teachers need to be educated on the need to develop and discuss assessment plan with their students so that the students will be well informed.

The Social Studies syllabus for the JHS in Ghana (2007) spelt out the composition of the SBA within a term. Every school term is supposed to have four tasks. The first and the third tasks are supposed to be individual test or quiz while the second and the fourth tasks are supposed be group work and project work respectively. The responses from the teachers on the number of different assessment modes conducted within the previous school term are displayed in Table 2 .

Table 2. Number of assessment conducted in the previous term

\begin{tabular}{|c|c|c|c|c|c|c|c|c|c|c|}
\hline \multirow[b]{3}{*}{ Item } & \multicolumn{10}{|c|}{ Number of assessment } \\
\hline & \multicolumn{2}{|c|}{0} & \multicolumn{2}{|c|}{1} & \multicolumn{2}{|c|}{2} & \multicolumn{2}{|c|}{3} & \multicolumn{2}{|c|}{$\geq 4$} \\
\hline & $\mathrm{F}$ & $\%$ & $\mathrm{~F}$ & $\%$ & $\mathrm{~F}$ & $\%$ & $\mathrm{~F}$ & $\%$ & $\mathrm{~F}$ & $\%$ \\
\hline Quizzes & & & 22 & 55 & 8 & 20 & & & & \\
\hline Class exercise & & & & & & & & & 40 & 100 \\
\hline Group work & 10 & 25 & 30 & 75 & & & & & & \\
\hline Assignment / Homework & & & & & & & & & 40 & 100 \\
\hline Attitudinal assessment & 32 & 80 & 8 & 20 & & & & & & \\
\hline Project work & 7 & 17.5 & 10 & 25 & 23 & 57.5 & & & & \\
\hline Interview & 31 & 77.5 & 9 & 22.5 & & & & & & \\
\hline Observation & & & & & & & & & 40 & 100 \\
\hline
\end{tabular}

Table 2 shows that the teachers use variety of assessment modes. Awoniyi and Fletcher ${ }^{[25]}$ believed that different forms of assessment should be conducted to make assessment comprehensive. Boadu and Asare-Danso ${ }^{[2]}$ therefore encourage teachers to adopt different assessment forms such as test, home/assignment, projects, interviews and 
observation. All the teachers interviewed indicated that they gave four or more class exercises and homework even though these are not essential tasks under the SBA. It could be observed at Table 2 that ten $(25 \%)$ and seven (17.5\%) did not give group work and project work respectively though they are requirement under the SBA. In addition, eighty percent of them did not conduct attitudinal assessment even though attitudes and values cover $50 \%$ of the $\mathrm{SBA}^{[26]}$. This agrees with Boadu and Asare-Danso ${ }^{[2]}$, when they indicated that most teachers neglect the affective domain in assessment. All of them however use observation as a form of assessment. The analysis from Table 2 shows that even though the social studies teachers in Biakoye District conduct different assessment modes, they do not effectively use the SBA guidelines.

\section{Benefits of school-based assessment}

Many experts outline benefits of using SBA. The Ministry of Education (2007) indicated that SBA reduces teachers' workload on assessment by sixty four percent. The findings show that there are a lot of benefits in the using of SBA.

Results from the interviews revealed a lot of benefits of SBA. SBA makes assessment comprehensive, enables teachers to know the strengths and weaknesses of learners, helps teachers to improve their teaching methods and techniques and provides immediate feedback to the students.

The SBA has a lot of benefits. It gives us the platform to use broad range of assessment methods to assess our students. You could use test, quizzes, class exercises and projects. As a teacher, you know your students better so you are able to give them assessment tasks appropriately. It helps you to know you students well, those who are very good and those who are weak. After assessment you easily give feedback. It also makes the students to be serious with their studies (Field interview, participant \#2).

After every lesson, we give exercises and this helps us to know whether our objectives are achieved or not. In Social Studies, we have to assess attitudes and values. This is achieved through SBA. The SBA helps me to improve my teaching practice. This is because after evaluation I do reflective practice and this helps me to improve my teaching strategies. It also motivates the students to work hard because feedback is given. We use the marks generated from SBA to advise parents on the performance of their children (Field interview, participant \#3).

SBA equips us with skills to design assessment items. In this system, the assessment is developed by us. It provides us with the opportunity to assess the students in different dimensions. Assessment is not limited to test alone. We give exercises, quizzes, assignments and projects. Though it is very tedious, it helps the students a lot (Field interview, participant \#5).

For SBA, it is very useful. It improves teaching and learning. In every lesson, you assess the students. This makes the students to be used to quizzes and this helps them not to fear examinations so much. Sometimes, some of the questions they do as exercises come in the examinations and they are able to do well. The marks from SBA form part of the final grading system and this makes the students to be serious (Field interview, participant \#4).

The Social Studies teachers were also asked to rate the benefits of SBA and their responses are displayed in Table 3. 
Table 3. Benefits of SBA

\begin{tabular}{|c|c|c|c|c|c|c|c|c|c|c|}
\hline \multirow[b]{2}{*}{ Item } & \multicolumn{2}{|c|}{1} & \multicolumn{2}{|c|}{2} & \multicolumn{2}{|c|}{3} & \multicolumn{2}{|c|}{4} & \multicolumn{2}{|c|}{5} \\
\hline & $\mathrm{F}$ & $\%$ & $\mathrm{~F}$ & $\%$ & $\mathrm{~F}$ & $\%$ & $\mathrm{~F}$ & $\%$ & $\mathrm{~F}$ & $\%$ \\
\hline SBA standardizes the practice of assessment & & & & & & & 35 & 87.5 & 5 & 12.5 \\
\hline $\begin{array}{l}\text { SBA Provides teachers with guidelines } \\
\text { for constructing assessment items }\end{array}$ & & & & & & & 22 & 55 & 18 & 45 \\
\hline SBA provides guidance in grading assessment tasks & & & & & & & 24 & 60 & 16 & 40 \\
\hline $\begin{array}{l}\text { SBA is used to provide feedback and } \\
\text { to improve instructional strategies }\end{array}$ & & & & & & & 10 & 25 & 30 & 75 \\
\hline $\begin{array}{l}\text { SBA is for the purpose of grading students } \\
\text { at the end of the term }\end{array}$ & & & & & & & 15 & 37.5 & 25 & 62.5 \\
\hline SBA motivates students to learn. & & & & & & & 15 & 37.5 & 25 & 62.5 \\
\hline SBA reduces the fear for external examination & & & & & & & 36 & 90 & 4 & 10 \\
\hline SBA is used to prepare students for external examination & & & & & & & 26 & 65 & 14 & 35 \\
\hline $\begin{array}{l}\text { SBA enhances the efficacy of my instructional } \\
\text { strategies as a Social Studies teacher }\end{array}$ & & & & & & & & & 40 & 100 \\
\hline SBA improves learning & & & & & & & 8 & 20 & 32 & 80 \\
\hline SBA is used to provide guidance and counseling to students & & & & & & & 25 & 62.5 & 15 & 37.5 \\
\hline SBA is used to generate marks for WAEC & & & & & 8 & 20 & 17 & 42.5 & 15 & 37.5 \\
\hline SBA makes assessment to comprehensive & & & & & & & 5 & 12.5 & 35 & 87.5 \\
\hline
\end{tabular}

1. Strongly disagree, 2. Disagree, 3. Uncertain, 4. Agree, 5. Strongly agree

Table 3 shows that most of the respondents either agreed or strongly agreed to all the items as benefits of SBA. All of them strongly agreed that SBA enhances the efficacy of their instructional strategies It could also be observed from Table 3 that 87.5 per cent strongly agreed that SBA makes assessment to comprehensive while 80 per cent and 60 per cent respectively strongly agreed that SBA improves learning and it is used to provide feedback and this helps to improve instructional strategies. It could also be observed from Table 3 that other benefits of SBA according to the responses from the teachers are; it standardizes the practice of assessment, provides teachers with guidelines for constructing assessment items, provides guidance in grading assessment tasks, motivates students to learn and prepares students for external examination.

Many writers also agreed to most of the items listed in Table 3 as benefits of SBA. Several studies acknowledge the benefits of SBA on teaching and learning. Basically, these include improvement in the effectiveness of teaching and learning process, providing stable and continuous pressure-free assessment, reducing the reliance on standardized examination, improving test item reliability, reflecting students' ability, fostering teaching, enforcing independent learning, facilitating learning autonomy and empowering teachers in the evaluation process ${ }^{[22,27]}$. In addition, SBA ensures that teachers verify learners' performance and use feedback to improve learning outcomes ${ }^{[29]}$.

\section{Conclusions}

The social studies teachers in Biakoye District attempt to follow the SBA guidelines even though most of them have not received any training on the use of the SBA. However the majority of the social studies teachers in the district do not prepare assessment plan in line with the guideline provided in the syllabus.

Assessment of students in social studies should be comprehensive in order to cover the three domains of learning. In order to ensure this, the teachers give variety of assessment forms ranging from quizzes to projects, class exercises and assignments without paying attention to weights in profile dimension and the SBA guidelines. Therefore, the majority of the teachers $(80 \%)$ neglected attitudinal assessment and some of them did not give assessment in project and group work which are basic requirement under the SBA. Analysis of the responses indicates that though the Social Studies teachers in Biakoye District gave variety of assessment tasks they were not strictly following the SBA guidelines. The assessment may therefore achieve the intended outcome.

It was realised from the analysis that SBA has a lot of benefits. It enhances the efficacy of instructional strategies, makes assessment comprehensive, provides feedback to improve instructional strategies, standardizes the assessment practices, provides teachers with guidelines for constructing assessment items, provides guidance in grading assessment tasks, motivates students to learn and prepares students for external examination. The SBA is a useful assessment system. 


\section{Recommendations}

Social Studies teachers should endeavour to make their assessment comprehensive. They should incorporate attitudinal assessment in their assessment modes. This is very important because the major goal of Social Studies is citizenship education. The pillar of citizenship education is the development of positive attitudes and values. There should be a deliberate attempt by social studies teachers to assess attitudes.

In addition, the Ghana Education Service should organise in-service training for social studies teachers on the use of SBA. Though the syllabus provides some guidelines, the teachers need to be educated on the various tasks and weighing of profile dimensions under the SBA especially project work and attitudinal assessment.

The following recommendations should also be taking into consideration.

- The teachers should also be trained on the need to have assessment plan and discussion of the plan with their students.

- The schools in the district should design their academic calendar including all key activities.

- The headmasters in the district should design tracking forms to check the conduct of SBA. This will ensure that teachers strictly follow the SBA guidelines.

- There should be school-based professional development sessions (PDS) for the teachers.

- Key stakeholders such as School Management Committees and Parent and Teachers' Association should collaborate with school authorities to ensure the effectiveness of SBA.

\section{References}

[1] Yidana, M, B., Boadu, K. Methods of teaching Social Studies. Cape Coast: CCE Publications; 2011.

[2] Boadu K., Asare-Danso S. An introduction to curriculum studies. Accra: Mantdik Printing and Publications; 2015.

[3] Akinsola, O. S. Teacher perception of school-based assessment problems: Implications for universal basic education. Nigerian journal of Educational Researcher and Evaluation. 2007; 7(1): 43-49.

[4] National Teaching Council. National Teachers'Standard for Ghana Guidelines. Accra: Ministry of Education; 2017.

[5] Ghazali, N.H.C. The implementation of school-based assessment system in Malaysia: A study of teacher perceptions. Malaysian Journal of Society and Space. 2016; 12(9): 104-117.

[6] Kwabia, K. Theory in Social Research: The Link between Literature and Observation. Accra: Woeli Publishing Services; 2006.

[7] Onuka, A.O.U., Oludipe, B. P. Systematic school based assessment for an improved cognitive achievement. Academic Journal of Research Development. 2006; 1(1): 1-2.

[8] Hargreaves, E. Teachers' feedback to pupils: "Like so many bottles thrown out to sea"? In R. Berry. \& B. Adamson (Eds.) Assessment reform in education: Policy and practice. Dordrecht: Springer; 2011. p.121-133.

[9] Clark, I. Formative assessment: Policy, perspectives and practice. Florida Journal of Educational Administration \& Policy. 2011; 4(2): 158-180.

[10] Awoyemi, M. O., Ndagunnu S.Y. Fundamentals of Social Studies. Ilorin: Roserich Publication; 2005.

[11] Ministry of Education. Teaching Syllabus for Social Studies (Junior High School). Accra: CRDD; 2012.

[12] Majid, F. A. SBA in Malaysian schools: The concern of the English teachers. US-China Education Review. 2011; $8(10)$.

[13] Boadu K., Kwenin I. A. Methods of teaching social studies as basic school level. Cape Coast: UCC College of Distance Education; 2015.

[14] Asemanyi, A. A, Watson-Nortey N. K. L. Levels of comprehension questions in junior high school English language textbooks. The Social Educator. 2017; 4(1).

[15] Adediwura, A. Teachers' perception of school-based assessment in Nigerian Secondary Schools. Mediterranean Journal of Social Sciences. 2012; 3(1): 99-110.

[16] Yidana, M. B., Boadu, K. Introduction to Social Studies. Cape Coast: CCE Publications; 2012.

[17] Ayaaba, D. A., Odumah, L. K. Skills and techniques of teaching Social Studies. Accra: Salt \& Light Publishing; 2013.

[18] Ankomah, Y. A, Oduro, G. K. T. Improving learning through formative assessment: The lecture's dilemma. Makerere Journal of Higher Education. 2004; 1: 131-140.

[19] Whyte, W. F. (ed). Participatory Action Research. Newbury Park, CA: Sage Publications; 2006.

[20] National Council for Curriculum and Assessment. Teaching Syllabus for Social Studies (Junior High School). Accra: Ministry of Education; 2019.

[21] Boss, S. The challenge of assessing project-based learning. District Administration. 2012; 48(9): 46-52.

[22] Bell, B., Cowie, B. Formative assessment and science education. Dordrecht: Kluwer; 2001. 
[23] Trumbull, E., Lash, A. Understanding Formative Assessment: Insights from Learning Theory and Measurement Theo$r y$. West Ed, San Francisco; 2013.

[24] Harlen, W. Teaching, learning and assessing 5-12 (4108th Ed.). London: Paul Chapman; 2005.

[25] Awoniyi F. C., Fletcher J. Senior high school mathematics teachers' use of school-based assessment guidelines and test scores in the Cape Coast Metropolis of Ghana. Journal of Educational Development and Practice. 2013; 4(1): 1940.

[26] Ministry of Education. Teaching Syllabus for Social Studies (Junior High School). Accra: CRDD; 2007.

[27] Yong, H. T., Lim, C. S. Implementing school-based assessment: The Mathematical thinking assessment (MATA) Framework. Buku Koleksi Bahan: Inovasi Pedagogi; 2008.

[28] National Teaching Council. National Teachers'Standard and Teacher Education Curriculum framework for Ghana: Handbook for PD Coordinators. Accra: Ministry of Education; 2016.

[29] Onuka, A.O. U., Amoo, S.A. Ensuring effective use of school based assessment in science, technology and mathematics and business study in the universal basic education. Nigeria Journal of Educational Research and Evaluation. 2007; 7(10): 86-98.

[30] Dada, M. F., Agbana, E. O., Adetayo, T. Counselling needs of sandwich students of university of Ado-Ekiti, College of Education, Oro Campus Kwara State, Nigeria. The Nigerian Journal of Guidance and Counselling. 2010; 15(1): $35-50$.

[31] Yakubu, A. K., Awabil, G., Forde, L. N. D. Counselling needs of students in the University of Health and Allied Sciences in Ghana. Journal of Educational Development and Practice (JED-P). 2017; 1(1): 1-13.

[32] Gray, D.E. Doing Research in the Real World. California: Sage Publications Ltd; 2009.

[33] Fraenkel, J. R., Wallen, N. E. How to design and evaluate research in education (6th ed.). New York, NY: McGraw-Hill; 2006. 